Original Article

\title{
Perceived Self-Efficacy Regarding Neonatal Care among Postnatal Mothers of Selected Manipal Group of Hospitals in Udupi District Karnataka
}

\author{
Binu Thapa ${ }^{1}$, Sonia R.B. D' Souza ${ }^{2}$, Pratibha Kamath ${ }^{3}$
}

Lecturer ${ }^{1}$, Kathmandu University School of Medical Sciences, Nepal, Professor ${ }^{2} \&$ Assistant Professor ${ }^{3}$, Obstetrics and Gynecological Nursing, M anipal College of Nursing, Manipal University, M anipal.

* Corresponding Author : Binu Thapa, Lecturer, Kathmandu University School of M edical Sciences, Nepal.

Mobile: +9779841514812, E-mail : binuthapa91@yahoo.com.

Received :08.12.2015

Review Completed : 26.07.2016

Accepted

$: 04.08 .2016$

Keywords: Perceived self-efficacy, Neonatal care and postnatal mothers.

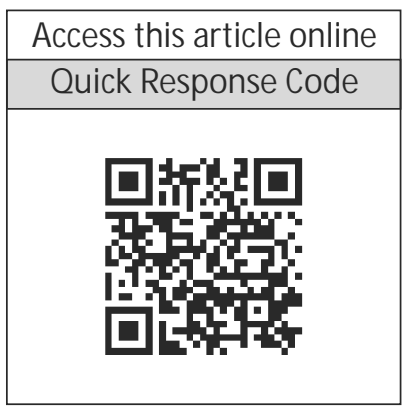

\begin{abstract}
:
Introduction : Perceived self efficacy is defined as people's beliefs about their capabilities to produce designated levels of performance that exercise influence over events that affect their lives. Self efficacy beliefs determine how people feel, motivate them and behave. ${ }^{2}$ A strong sense of efficacy regarding neonatal care enhances the mother's success to take care of newborn baby and promote well being of their baby.
\end{abstract}

Objectives: The objective of the study was to determine the perceived self-efficacy on neonatal care among primigravida and multigravida postnatal mothers.

Methods : A descriptive survey was conducted among 166 postnatal mothers in the Kasturba Hospital, Manipal and Dr. T.M.A. Pai Hospital of Udupi District Karnataka, India. Purposive sampling technique was used. The data was collected using structured perceived self-efficacy scale on neonatal care. The data was categorized and analyzed by using SPSS 16.0 version.

Result : The study found that $50.6 \%$ of the mothers had high perceived self efficacy and $49.4 \%$ had low perceived efficacy on neonatal care.

Conclusion: This study shows that nearly half of the mothers have low perceived self efficacy on neonatal care, which shows that they need further education on how to provide newborn care that may help them to have high aspirations and strong commitment to take care of their baby.

\section{Introduction}

Perceived self-efficacy is concerned with people's beliefs in their capability to produce given attainments. ${ }^{1}$ Self efficacy is the belief that one has the power to produce that effect by completing a given task or activity related to that competency. Self efficacy relates to a person's perception of their ability to reach a goal. It is the belief that one is capable of performing in a certain manner to attain certain goals. $^{2}$

Every neonate has the right to grow up in a healthy environment. The future development of neonates depends on their obtaining in good health. A newborn baby is precious not only to their parents, but also to their community, nation and to the world at large since today's newborns are the citizens of tomorrow. ${ }^{3}$
Worldwide, about two-thirds of infant deaths occur in the first month of life, two-thirds of those numbers die in the first week of life. Of those, two-thirds die in the first 24 hours of life. The neonatal period is a highly vulnerable time for an infant, who is completing many of the physiologic adjustments required for extra-uterine existence. Most newborn deaths are entirely preventable through a number of simple and low-cost actions that can be taken by health care workers, mothers, families and the community for better care of newborns to put them on the road to a healthylife. ${ }^{4}$

High perceived self efficacy of neonatal care by mothers accordingly plays an important role in reducing mortality as well as morbidity, because they will have enough confidence to take care of their newborn baby, which helps 
to provide quality care and prevent any deviation from normal health. Skilled professional care during pregnancy, at birth and during the postnatal period is essential to enhance the knowledge and practice of neonatal care. ${ }^{5}$

So, new born care is an essential component of an effective health care delivery system to maintain the optimal health of a newborn and reduce their mortality and morbidity. ${ }^{6}$ Literature describes self efficacy of mothers as directly related to their ability to adopt healthy practices for newborn care. So the researcher felt the need to assess the perceived self efficacy on neonatal care among postnatal mothers.

\section{Materialsand Methods}

A descriptive survey design was used in this study. Study was conducted at the postnatal wards of Kasturba Hospital, Manipal, India, and Dr. T.M.A. Pai Hospital, Udupi, Karnataka, India. Data was collected from $14^{\text {th }}$ January to $17^{\text {th }}$ February 2013. The sample populations were the postnatal mothers who had undergone either vaginal delivery or cesarean section delivery and admitted to the postnatal wards. The sample size was 166 including both primigravida and multigravida women who have a viable newborn to provide care. A non-probability, purposive sampling technique was used. The following data collection tools were developed by the researcher for the present study.

Tool 1 : Demographic Proforma.

Tool2 : Perceived Self efficacy Scale Regarding Neonatal Care.

The demographic proforma was developed by the investigator to collect the demographic data of the sample. It consisted of 10 items. The investigator developed a Perceived Self-efficacy Scale for Neonatal Care. The tool consisted of 22 items on a five points likert type scale, the options being 'Strongly Disagree', 'M oderately Disagree', 'Neither Agree nor Disagree', 'Moderately Agree', or 'Strongly Agree'. There were no negative statements. The items were scored as Strongly Agree $=5$, Moderately Agree $=4$, Neither Agree nor Disagree $=3$, moderately
Disagree $=2$ and Strongly Disagree $=1$. The maximum score was 110 and the minimum score was 22 and it was classified as low self- efficacy and high self efficacy with a score of $22-55(<50 \%)$ and $56-110(>50 \%)$ respectively.

To ensure the content validity, the tool along with the problem statement, objective and criteria checklist were submitted to seven experts of different field of Nursing. The pretesting was done among five mothers of newborns to determine the clarity. Reliability test was done among 20 samples by using Cronbach's alpha technique where $r$ $=0.73$. Hence the tool was found to be reliable. The tools were administered on the $2^{\text {nd }}$ postnatal day for postnatal mothers who had a vaginal delivery and on the $6^{\text {th }}$ postnatal day for postnatal mothers who had a caesarean section delivery to reduce the biases.

Administrative permission was obtained from Dean, Manipal College of Nursing, Manipal. Medical superintendent, Kasturba Hospital and Dr. T.M.A. Pai Hospital, Udupi, the institutional ethical committee, Kasturba Hospital, Manipal. Informed consent was obtained from each participant. The purpose of the study was explained to the participants and confidentiality of responseswas assured.

After assessing the perceived self efficacy, an informational video on neonatal care was developed and distributed to the respective hospital for enhancing the mother's ability to take care of her newborn baby.

\section{Results}

\section{Demographic Characteristics}

With regard to the sample characteristics, out of 166 respondents, majority i.e.77 (46.4\%) belong to the age group of 26-30 years, 148 (89.2\%) were Hindus, 49 (29.5\%) had higher secondary education, 113 (68.1\%) were housewives, and 94 (56.6\%) belong to a joint family. Most of the postnatal mothers $62(37.3 \%$ ) had a family income of rupees 5,001 to 10,000/month and 49 (29.5\%) had taken antenatal care from a district hospital. 95 (57.2\%) were primigravida postnatal mothers and 71 (42.8\%) were multigravida postnatal mothers. 94 (56.6\%) postnatal 
mothers had given birth by cesarean section delivery and $72(43.4 \%)$ had given birth by vaginal delivery.

\section{Perceived self efficacy on neonatal care}

Half of the respondents i.e. 84 (50.6\%) had high perceived self efficacy and 82 (49.4\%) had low perceived self efficacy on neonatal care.

Out of 71 multigravida mothers, the majority i.e. 51 (71.8\%) had high self efficacy and only $20(28.2 \%)$ had low self efficacy regarding neonatal care. Whereas, out of the 95 primigravida postnatal mothers, the majority i.e. 62 (65.3\%) had low self efficacy and only 33 (34.7\%) had high self efficacy.

The data was further analyzed to compare perceived selfefficacy on neonatal care among primigravida and multigravida postnatal mothers. The M ann- Whitney U test was used. The findings are presented in Table 1.

The data presented in Table 1 shows that there is a significant difference in perceived self-efficacy between primigravida and multigravida postnatal mothers ( $Z=$ $4.751, p=0.001$ ) at 0.05 level of significance.

Table 1: Comparison of perceived self-efficacy in neonatal care among primigravida and multigravida postnatal mothers

$n=166$

\begin{tabular}{|l|c|c|c|c|}
\hline Group Variable & Median & IQR & Z value & P value \\
\hline Primi & 50 & $39-65$ & \multirow{2}{*}{4.751} & \multirow{2}{*}{$0.001^{*}$} \\
\cline { 1 - 3 } M ulti & 78 & $55-8$ & & \\
\cline { 1 - 3 }
\end{tabular}

(*significant)Z=1.96( $p<0.05)$

\section{Discussion}

In the present study, the majority of the postnatal mothers $84(50.6 \%)$ had high perceived self efficacy on neonatal care. Among multigravida postnatal mothers, a majority of 51 (71.8\%) had high perceived self efficacy and 20 (28.2\%) had low perceived self efficacy on neonatal care. Whereas among primigravida postnatal mothers, a majority of 62 (65.3\%) had low perceived self efficacy and $33(34.7 \%)$ had high perceived self efficacy.

There was a significant difference in perceived self-efficacy regarding neonatal care between primigravida and multigravida postnatal mothers $(\mathbf{Z}=4.751, p=0.001)$ at 0.05 level of significance. It is inferred that experience helps to have high perceived self efficacy.

There is so far no study conducted to assess the perceived self efficacy regarding neonatal care among postnatal mothers. So, the authors are unable to include and discuss the findings of others studies.

\section{Conclusion}

The findings of the study showed that half of the respondents had high perceived self efficacy on neonatal care. Nearly half of the mothers have low perceived self efficacy on neonatal care. Majority of multigravida mothers had high perceived self efficacy. There was a significant difference in perceived self-efficacy regarding neonatal care between primigravida and multigravida postnatal mothers. There are no studies found on this area, hence more studies need to be conducted to identify the perception of self efficacy and factors affecting it so that proper interventions can be implemented to enhance the perception of self efficacy, which would help the mother to provide appropriate care to her baby and help to decrease neonatal morbidity as well as mortality

\section{References}

1. Bandura A, guide for constructing self-efficacy scales, 1997

2. Bandura A. self efficacy. Encyclopedia of human behavior vol 4, New York.

3. Padmavathi B, A holistic approaches towards healthy infant, Nightingale Nursing Times, volume 8 no 3, june 2012.

4. BeckD, Ganges F, Goldman S, Phyllis L. Care of the Newborn, Reference Manual, saving new born life.

5. Upadhyay R, Chinnakali P, Odukoya O, Yadav K, Sinha S, Daral S, et al. High Neonatal M ortality Rates in Rural India: What Options to Explore? Review Article, ISRN Pediatrics, Volume 2012.

6. Parlato R, Darmstadt G, Tinker A. saving newborn lives tools for newborn health, Saving Newborn Lives Initiative Washington, DC, 2004 